EPJ Web of Conferences 110,01068 (2016)

DOI: $10.1051 /$ epjconf/201611001068

(C) Owned by the authors, published by EDP Sciences, 2016

\title{
ANALYSIS OF THE PROPERTIES OF WORKING SUBSTANCES FOR THE ORGANIC RANKINE CYCLE BASED DATABASE "REFPROP"
}

\author{
Galashov Nikolay ${ }^{1, a}$, Tsibulskiy Svyatoslav ${ }^{1, b}$, Serova Tatiana ${ }^{1}$ \\ ${ }^{1}$ National Research Tomsk Polytechnic University, 634050 Tomsk, Russia
}

\begin{abstract}
The object of the study are substances that are used as a working fluid in systems operating on the basis of an organic Rankine cycle. The purpose of research is to find substances with the best thermodynamic, thermal and environmental properties. Research conducted on the basis of the analysis of thermodynamic and thermal properties of substances from the base "REFPROP" and with the help of numerical simulation of combined-cycle plant utilization triple cycle, where the lower cycle is an organic Rankine cycle. Base "REFPROP" describes and allows to calculate the thermodynamic and thermophysical parameters of most of the main substances used in production processes. On the basis of scientific publications on the use of working fluids in an organic Rankine cycle analysis were selected ozone-friendly lowboiling substances: ammonia, butane, pentane and Freon: R134a, R152a, R236fa and R245fa. For these substances have been identified and tabulated molecular weight, temperature of the triple point, boiling point, at atmospheric pressure, the parameters of the critical point, the value of the derivative of the temperature on the entropy of the saturated vapor line and the potential ozone depletion and global warming. It was also identified and tabulated thermodynamic and thermophysical parameters of the steam and liquid substances in a state of saturation at a temperature of $15{ }^{\circ} \mathrm{C}$. This temperature is adopted as the minimum temperature of heat removal in the Rankine cycle when working on the water. Studies have shown that the best thermodynamic, thermal and environmental properties of the considered substances are pentane, butane and R245fa. For a more thorough analysis based on a gas turbine plant NK36ST it has developed a mathematical model of combined cycle gas turbine (CCGT) triple cycle, where the lower cycle is an organic Rankine cycle, and is used as the air cooler condenser. Air condenser allows stating material at a temperature below $0{ }^{\circ} \mathrm{C}$. Calculation of the parameters of all substances in the model are based on a base "REFPROP". Numerical investigations on this model showed that the highest net efficiency will be at work on pentane. Butane and R245fa have the same net efficiency, for $0.8 \%$ lower than pentane. Ammonia has a net efficiency of $2.5 \%$ is lower than pentane. CCP net efficiency strongly depends on the condensation temperature of the substance, as for pentane at lower temperature of condensation at $10{ }^{\circ} \mathrm{C}$ it is increased by $1 \%$.
\end{abstract}

a Corresponding author: gal@tpu.ru

b Corresponding author: stzibulsky@tpu.ru

This is an Open Access article distributed under the terms of the Creative Commons Attribution License 4.0, which permits unrestricted use, distribution, and reproduction in any medium, provided the original work is properly cited. 


\section{Introduction}

Organic Rankine Cycle (ORC) - is a cycle, the working substance of which are low-boiling substances (LBS). Use as a working substance of the LBS allows to solve a number of problems existing water as the working medium: lower the temperature of the heat removal through the use of air condensers in the winter and increase the efficiency of this cycle; due to a high density to reduce the size, weight and cost of the units; by condensing steam at high pressures to reduce or eliminate air suction to the condenser and to improve heat transfer there in. Application of air condensers in the ORC can also eliminate or significantly reduce the consumption of water for technological purposes. Therefore recently in the scientific literature appeared a large number of studies on the use of ORCs [1-9]. Basically, the ORC is used to generate electricity from of low potential waste heat, but as shown in $[10,11]$ it can be used in a combined cycle gas turbine (CCP) and schemes of powerful units thermal and nuclear power. Economic, safety and environmental performance of the ORC are highly dependent on the type of the LBS. Environmental cleanliness LBS is determined ozone depletion potential (ODP) and global warming potential (GWP).

\section{Select the substances and analysis based on database REFPROP}

In this paper, for the analysis and selection of the LBS for the cycle used by the ORC database "REFPROP" [12], that allows calculate the thermodynamic and thermophysical parameters of most substances used in production processes.

Currently, low-boiling substances are separated into four groups.

Ozone-depleting chlorofluorocarbons (CFCs) and hydrochlorofluorocarbons (HCFCs): R11, R12, R12B1, R13, R13B1, R21, R22, R113, R114, R115, R123, R124, R141b, R142b, R502, R503, R504. These LBS halogen derivatives are homologous series of methane, ethane and propane. The molecules of these substances are present fluorine, bromine, chlorine.

Transitional hydrochlorofluorocarbon (HCFC): R401, R401B, R401C, R402A, R402B, R403A, R403B, R405A, R406A, R408A, R409A, R409B, R411A, R411B, R412F, R509, C10M1, C10M2.

Ozone-friendly hydrofluorocarbons (HFCs): R23, R32, R125, R143a, R161, R128, R134a, R152a, R131, R227ea, R326fa, R245fa, R116, RC318, RE347mcc, R846, HFO-1234yf.

Natural: air (R729), ammonia (R717), carbon dioxide (R744), ethane (R170), propane (R290), isobutane (R600a), butane (R600), cyclopropane (C270), cyclopentane (R1270), dimethyl ester (RE170).

For the analysis were selected most highly recommended recently in scientific publications for use in refrigeration, heat pumps and ORCs ozone-friendly natural and synthetic LBS ammonia, butane, pentane, R134a, R152a, R236fa and R245fa. Since at present the main working body of the Rankine cycle is water, to compare and contrast also considered its options.

For selected substances in the Table. 1-3 given on the basis of certain base "REFPROP" thermal and thermodynamic parameters, which refer to the following parameters: $M$ - molecular weight; $t_{\mathrm{tp}}-$ the temperature of the triple point; $t_{0}$ - boiling point at atmospheric pressure of $98 \mathrm{kPa} ; t_{\mathrm{cr}}-$ the critical temperature; $R_{\mathrm{tp}}$ - critical pressure; $\rho_{\mathrm{cr}}$ - critical density; $\xi$ - value of the derivative $d T / d S$ at a saturated steam line; $P_{\mathrm{s}}$ - the saturation pressure; $\rho$ - the density; $\mathrm{h}-$ enthalpy; $s-$ the entropy; $c_{\mathrm{p}}-$ specific heat in the isobaric process; $\mu$ - dynamic viscosity; $P r-$ Prandtl number; $\lambda-$ thermal conductivity; $r$ - specific heat of vaporization; $H_{0}$ - enthalpy difference in isentropic process enthalpy of saturated steam at a temperature of the LBS to $100{ }^{\circ} \mathrm{C}$ saturation vapor pressure at $15{ }^{\circ} \mathrm{C}$; index ' indicates that the parameter is on the saturated liquid line, and "- on the saturated steam line.

Table 1. The properties of ozone-friendly LBS.

\begin{tabular}{|c|c|c|c|c|c|c|c|c|}
\hline LBS & $\begin{array}{c}\mathbf{M}, \\
\mathbf{g} / \mathbf{m o l}\end{array}$ & $\begin{array}{c}\boldsymbol{t}_{\mathrm{tp}}, \\
{ }^{\circ} \mathbf{C}\end{array}$ & $\begin{array}{c}\boldsymbol{t}_{\mathbf{0}}, \\
{ }^{\circ} \mathbf{C}\end{array}$ & $\begin{array}{c}\boldsymbol{t}_{\mathrm{cr}}, \\
{ }^{\circ} \mathbf{C}\end{array}$ & $\begin{array}{c}\boldsymbol{P}_{\text {cr }}, \\
\mathbf{M P a}\end{array}$ & $\begin{array}{c}\mathbf{P}_{\mathrm{cr}}, \\
\mathbf{m o l} / \mathbf{l}\end{array}$ & $\begin{array}{c}\boldsymbol{\xi}, \\
\mathbf{J} /\left(\mathbf{k g} \cdot \mathbf{K}^{\mathbf{2}}\right)\end{array}$ & $\begin{array}{c}\mathbf{G W P} \\
-\end{array}$ \\
\hline water & 18 & -0 & 100 & 374 & 22,06 & 17,87 & $-17,78$ & - \\
\hline
\end{tabular}




\begin{tabular}{|c|c|c|c|c|c|c|c|c|} 
ammonia & 17 & -78 & -33 & 132 & 11,33 & 13,21 & $-10,48$ & 3 \\
\hline butane & 58 & -138 & -1 & 152 & 3,80 & 3,92 & 1,03 & 3 \\
\hline pentane & 72 & -130 & 36 & 196 & 3,37 & 3,22 & 1,51 & 11 \\
\hline R134a & 102 & -103 & -26 & 101 & 4,06 & 5,02 & $-0,39$ & 1300 \\
\hline R152a & 66 & -119 & -24 & 113 & 4,52 & 5,57 & $-1,14$ & 120 \\
\hline R236fa & 152 & -93 & -1 & 125 & 3,20 & 3,70 & 0,76 & 9400 \\
\hline R245fa & 134 & -102 & 15 & 154 & 3,65 & 3,85 & 0,19 & 950 \\
\hline
\end{tabular}

Table 2. Thermophysical properties of liquid LBS at saturation temperature $t_{S}=15^{\circ} \mathrm{C}$.

\begin{tabular}{|c|c|c|c|c|c|c|c|c|c|}
\hline LBS & $\begin{array}{c}\boldsymbol{P}_{s}, \\
\mathbf{M P a}\end{array}$ & $\underset{\mathbf{k g} / \mathbf{m}^{3}}{\rho^{\prime},}$ & $\begin{array}{c}\mathbf{h}^{\prime}, \\
\mathbf{k J} / \mathbf{k g}\end{array}$ & $\begin{array}{c}\mathbf{s}^{\prime}, \\
\mathrm{kJ} /(\mathbf{k g} \cdot \mathbf{K})\end{array}$ & $c_{\mathrm{p}}{ }^{\prime}, \mathrm{kJ} /(\mathrm{kg} \cdot \mathrm{K})$ & $\begin{array}{c}\mu^{\prime}, \\
\mathbf{P a} \cdot \mathbf{s}\end{array}$ & $\begin{array}{l}\text { Pr', } \\
-\end{array}$ & $\begin{array}{c}\lambda^{\prime}, \\
\mathbf{W} / \mathbf{K}\end{array}$ & $\begin{array}{c}r, \\
\mathrm{~kJ} / \mathrm{kg}\end{array}$ \\
\hline water & 0,002 & 999 & 62 & 0,22 & 4,19 & 1142 & 8,12 & 589,1 & 2466 \\
\hline ammonia & 0,72 & 617 & 413 & 1,72 & 4,71 & 146 & 1,3 & 514,8 & 1207 \\
\hline butane & 0,18 & 584 & 235 & 1,12 & 2,39 & 175 & 3,8 & 108,9 & 372 \\
\hline pentane & 0,05 & 631 & -49 & $-0,16$ & 2,27 & 238 & 4,7 & 115,3 & 374 \\
\hline $\mathrm{R} 134 \mathrm{a}$ & 0,49 & 1244 & 220 & 1,07 & 1,39 & 221 & 3,58 & 85,5 & 187 \\
\hline R152a & 0,44 & 925 & 226 & 1,09 & 1,75 & 183 & 3,14 & 102,4 & 291 \\
\hline R236fa & 0,19 & 1393 & 218 & 1,06 & 1,24 & 325 & 5,25 & 76,7 & 152 \\
\hline $\mathrm{R} 245 \mathrm{fa}$ & 0,10 & 1366 & 219 & 1,07 & 1,30 & 465 & 6,63 & 91,3 & 196 \\
\hline
\end{tabular}

Table 3. Thermophysical properties of steam LBS at saturation temperature $t_{S}=15{ }^{\circ} \mathrm{C}$.

\begin{tabular}{|c|c|c|c|c|c|c|c|c|c|}
\hline LBS & $\begin{array}{l}P_{s}, \\
\text { MPa }\end{array}$ & $\begin{array}{c}\rho^{\prime \prime}, \\
\mathbf{k g} / \mathbf{m}^{3}\end{array}$ & $\begin{array}{c}\text { h", } \\
\text { kJ/kg }\end{array}$ & $\begin{array}{c}\mathbf{s}^{\prime \prime}, \\
\mathbf{k J} /(\mathbf{k g} \cdot \mathbf{K})\end{array}$ & $\begin{array}{c}c_{p} ", \\
\mathbf{k J} /(\mathbf{k g} \cdot \mathbf{K})\end{array}$ & $\begin{array}{l}\mu ", \\
\mathrm{~Pa} \cdot \mathbf{s}\end{array}$ & $\begin{array}{c}\text { Pr", } \\
\text { - }\end{array}$ & $\begin{array}{l}\lambda^{\prime \prime}, \\
\mathbf{W} / \mathbf{K}\end{array}$ & $\begin{array}{c}H_{0}, \\
\mathrm{~kJ} / \mathrm{kg}\end{array}$ \\
\hline water & 0,002 & 0,01 & 2528 & 8,78 & 1,90 & 9,59 & 1,02 & 17,9 & 558 \\
\hline ammonia & 0,72 & 5,70 & 1619 & 5,91 & 2,93 & 9,51 & 1,12 & 24,9 & 231 \\
\hline butane & 0,18 & 4,53 & 606 & 2,41 & 1,73 & 7,13 & 0,79 & 15,6 & 90 \\
\hline pentane & 0,05 & 1,43 & 325 & 1,13 & 1,65 & 6,66 & 0,83 & 13,3 & 94 \\
\hline R134a & 0,49 & 24,03 & 407 & 1,72 & 0,97 & 11,29 & 0,85 & 12,8 & 32 \\
\hline R152a & 0,44 & 14,34 & 517 & 2,10 & 1,18 & 9,69 & 0,84 & 13,6 & 57 \\
\hline R236fa & 0,19 & 13,07 & 370 & 1,59 & 0,85 & 10,49 & 0,75 & 11,9 & 35 \\
\hline R245fa & 0,10 & 6,13 & 415 & 1,75 & 0,92 & 9.92 & 0,75 & 12,2 & 46 \\
\hline
\end{tabular}

Table. 1 in terms of GWP see that natural LBS practically no impact on global warming, while at the synthetic LBS influence significantly.

Water is currently in power engineering is a basic substance as the working fluid in the Rankine cycle. Among its advantages include the high values of $r, H_{0}, \mathrm{c}_{\mathrm{p}}{ }^{\prime}$, and $\lambda^{\prime}$. However, it has significant disadvantages: a large negative value of $\xi=-17.78$, which requires superheating and leads to a significant loss of humidity in the turbine at low pressure; high triple point temperature $-0{ }^{\circ} \mathrm{C}$, which causes problems when working in the winter time and allows for heat removal in the temperature cycle below $15^{\circ} \mathrm{C}$; high viscosity liquid $\mu^{\prime}$ leads to high costs for power transfer pump; to obtain high 
values of efficiency requires high pressure and temperature at the top of the cycle and a high vacuum at the bottom, which creates a lot of problems with the selection of construction materials and providing vacuum. Due to these disadvantages is searched substances capable of replacing the water in the Rankine cycle. All considered the LBS, but water has a temperature of the triple point below $50{ }^{\circ} \mathrm{C}$, which determines their reliable operation in the winter time and the opportunity to remove the heat in the air condenser at very low temperatures.

Ammonia has a number of properties commensurate with the properties of water - has high values of $r, H_{0}, \mathrm{c}_{\mathrm{p}}$ ', and $\lambda^{\prime}$. The disadvantages of ammonia include: condensation pressure, which requires increased costs in the exhaust section of the turbine and the condenser; a large negative value $\xi=$ 10.48 , which leads to great losses on the humidity in the turbine; great pressure on the transfer pump that costly power for its own needs installation. Furthermore, ammonia is toxic, flammable and explosive, which greatly limits its use.

All other refrigerants have $\xi$ close to 0 , which allows them to work in the turbine without loss of moisture. Among them, butane, and pentane has the higher values of $r, H_{0}, \mathrm{c}_{\mathrm{p}}{ }^{\prime}$, and $\lambda^{\prime}$. As pentane advantages compared with butane has a higher molecular weight and a large critical temperature as high as a disadvantage $t_{0}$, which will cause the vacuum in the condenser at a temperature below $36{ }^{\circ} \mathrm{C}$. The common disadvantage is their flammability.

Freon R134a and R152a have the lowest boiling points, so they are more suitable for refrigeration machines. To their disadvantages can include high condensing pressure and lower critical temperature. $\mathrm{R} 152 \mathrm{a}$ has better properties than R134a on the following parameters: GWR, $r, H_{0}, \mathrm{c}_{\mathrm{p}}{ }^{\prime}, \mu^{\prime}$ and $\lambda^{\prime}$.

Most preferred for use in the ORC are R236fa and R245fa. The major disadvantage R236fa is the high value of GWP. As R245fa advantage compared to R236fa has great values $r, H_{0}$, and as a disadvantage a higher temperature $t_{0}$.

Thus, as a result of the analysis, we can rank the considered LBS as follows: pentane, butane, R245fa, R236fa, ammonia, R152a, R134a.

\section{Analysis using CCP model}

For a more profound analysis has been developed of the utilization scheme of CCP triple cycle (fig.1), in which the third cycle is an organic Rankine cycle. Fig. 1 shows the elements; 1 - the compressor; 2 - the combustion chamber; 3 - gas turbine; 4 - heat recovery steam generator (HRSG); 5 - turbine operating on water steam; 6 - turbines operating on LBS steam; 7 - electric generator; 8 - evaporatorcondenser; 9 - air condenser; 10 - the heat exchanger; 11 - the heat exchanger; 12,13 - pumps. In the installation is a first cycle Brayton cycle in which air compressed in an adiabatic process by the compressor 1 and enters the combustion chamber 2, where the constant pressure fuel is combusted. The hot gases with temperatures $1200-1500{ }^{\circ} \mathrm{C}$ enter the turbine 3 , which in an adiabatic process perform work, and a temperature of $450-650{ }^{\circ} \mathrm{C}$ is fed in the HRSG 4 in which heat transfer water of the second cycle, after which the temperature of $75-120{ }^{\circ} \mathrm{C}$ go to the chimney. The second cycle operates on the water. The water in the HRSG 4 in the isobaric process is converted into superheated steam which is at a pressure of $10-25 \mathrm{MPa}$ and a temperature of $400-600{ }^{\circ} \mathrm{C}$ is supplied to the turbine 5 , which performs the process in adiabatic operation and with $0.15-0.2 \mathrm{MPa}$ pressure goes evaporatorcondenser 8 , where the condensation process transfers heat LBS third cycle. The steam condensate by the pump 12 through the heat exchanger 11 is fed to HRSG 4. The third cycle is working on LBS. Low boiling substance in the condenser-evaporator 8 in the isobaric process is converted from a liquid to a saturated steam which is supplied to the turbine 6 where adiabatic process does work and goes through heat exchanger 10 in the air condenser 9, wherein in the isobaric process gives heat to the cooling air. LBS condensate by the pump 13 through the heat exchanger 10 and the heat exchanger 11 is fed to the condenser-evaporator 8 . Heat exchanger 10 is required for steam LBS go out from the turbine 6 in a superheated state, otherwise it can be removed. The heat exchanger 11 is used to cool condensate entering the HRSG 4 to $60{ }^{\circ} \mathrm{C}$, to prevent condensation of the humidity in the exhaust gases and operates without metal corrosion. Operation all turbine by using of the shaft is transmitted to a generator 7 , which produces electricity. 




Figure 1. CCP triple cycle.

On the basis of this scheme, developed the mathematical model for calculating performance CCP triple cycle. This model is based on a gas turbine plant NK-36ST, which has the following parameters: capacity of $25 \mathrm{MW}$; 36\% efficiency; gas consumption and temperature of the exhaust gases of 101.3 $\mathrm{kg} / \mathrm{s}$ and $457{ }^{\circ} \mathrm{C}$. For the water-steam cycle adopted the following parameters: pressure and temperature of the steam before the turbine $16 \mathrm{MPa}$ and $440{ }^{\circ} \mathrm{C}$; steam pressure at the turbine outlet of $0.2 \mathrm{MPa}$; the temperature of the water entering the waste heat boiler $60{ }^{\circ} \mathrm{C}$; the temperature of the exhaust gas heat recovery boiler $75^{\circ} \mathrm{C}$; temperature difference in the evaporator $8{ }^{\circ} \mathrm{C}$. Air condenser in an organic Rankine cycle allows reduce the temperature of condensation of LBS to the triple point, but the cooling air temperature must be below the condensation temperature of approximately $20{ }^{\circ} \mathrm{C}$. The model is implemented in the program package spreadsheet Excel. Calculation of the parameters of all substances in the program are based on database functions "REFPROP".

Numerical studies were conducted with this program for the selected of LBS above, with changing the condensation temperature of -30 to $30{ }^{\circ} \mathrm{C}$.

$\mathrm{CCP}$ efficiency gross and net depending on the condensing temperature and the kind of LBS that were obtained from the studies are shown in fig. 2.
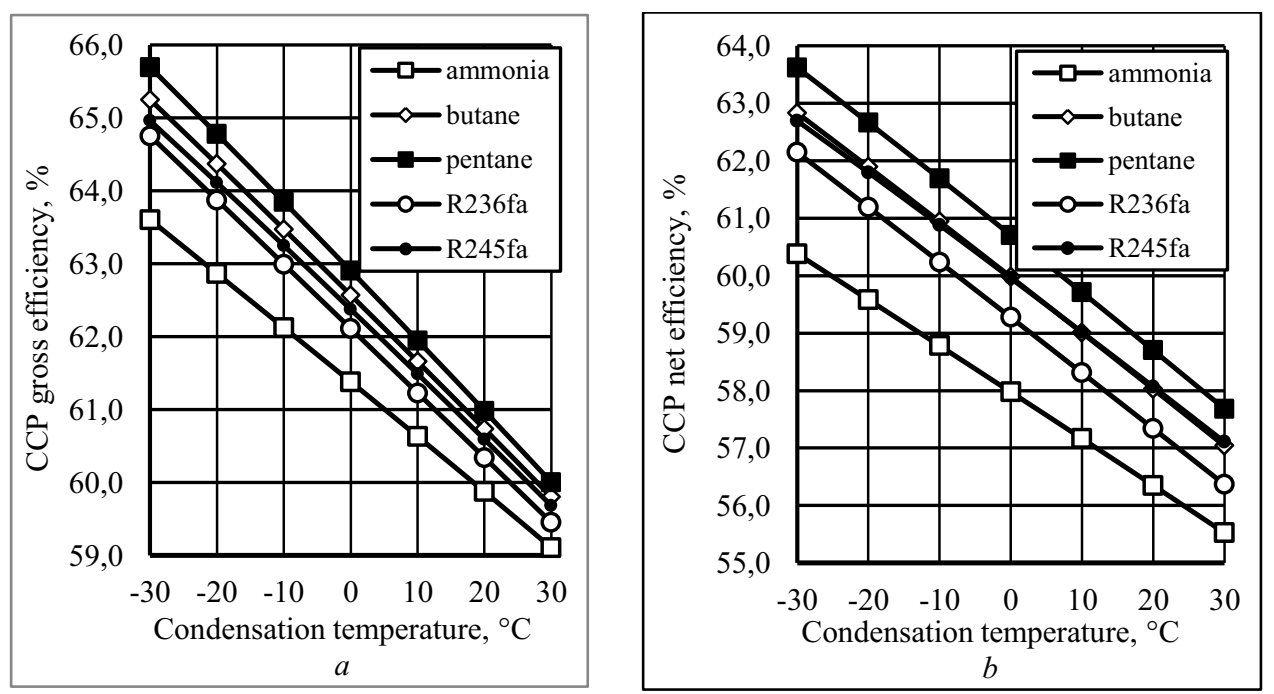

Figure 2. The dependence of efficiency CCP gross (a) and net (b) of the condensation temperature of LBS. 
Fig. 2 shows that net efficiency is the best pentane, in second place are butane and R245fa. At the last place is ammonia, which is associated with large losses from humidity in ammonia turbine and energy consumption for transfer pump.

\section{Conclusions}

- The most preferred are pentane, butane and R245fa as working substances for ORC.

- CCP gross and net efficiencies linearly depend on the condensation temperature of LBS. At lower temperatures of $10{ }^{\circ} \mathrm{C}$ pentane efficiency CCP net increases by $1 \%$.

- For CCP based on the gas turbine NK-36ST at work on pentane and its condensation temperature is below $0{ }^{\circ} \mathrm{C}$ can be obtained by CCP net efficiencies above $60 \%$.

The work has been done in framework of federal focused program implementation "Competitiveness Enhancement Program" of National Research Tomsk Polytechnic University.

\section{References}

1. S. Marco, A. Christos. Frangopoulos, M. Giovanni, S. Rech, A. Lazzaretto, Energy Conversion and Management, 92, 523 (2015)

2. B. Choi, Y. Kim, Energy, 54, 404 (2013)

3. U. Larsen, L. Pierobon, F. Haglind, C. Gabrieli, Energy, 55, 803 (2013)

4. G. Shu, L. Liu, H. Tian, H. Wei, G. Yu, Applied Energy, 113, 1188 (2014)

5. A. Toffolo, A. Lazzaretto, G. Manente, M. Paci, Applied Energy, 121, 219 (2014)

6. M. Yang, R. Yeh, Energy Convers Manage, 88 (12), 999 (2014)

7. T. Guo, H. Wang, S. Zhang, Energy, 40, 107 (2011)

8. A. Lazzaretto, G. Manente, Int J Thermodynamics, 17 (3), 173 (2014)

9. L. Branchini, A. De Pascale, A. Peretto,Applied Thermal Engineering, 61 (2), 129 (2013)

10. N. Galashov, S. Tsybulsky, Power Technology and Engineering, 48, 6 (2015)

11. A. Kanaev, I. Kopp, S. Kutateladze, VII Congress WEC (Moscow, 1968)

12. E. Lemmon, M. Huber, M. McLinden, Reference fluid thermodynamic and transport propertiesREFPROP (National Institute of Standard and Technology, 2007) 